\title{
Liquidity in the Futures Pits: Inferring Market Dynamics from Incomplete Data
}

\section{Joel Hasbrouck}

This Draft: March 18, 2003

Comments Welcome

Kenneth M. Langone Professor of Finance

Stern School of Business

New York University

Suite 9-190 Mail Code 0268

44 West Fourth St.

New York, NY 10012-1126

Tel: (212) 998-0310

Fax: (212) 995-4901

E-mail: jhasbrou@stern.nyu.edu

Web: http://www.stern.nyu.edu/ jhasbrou

For comments on an earlier draft, I am grateful to Larry Harris, Ken Kavajecz, Peter Locke, Nick Polson, the Chicago Mercantile Exchange, and seminar participants at Duke University, the University of Chicago, Vanderbilt University, Wharton and the Western Finance Association. I am grateful for financial support from a Stern Summer Research Grant. An appendix that describes the computational details of this paper, and all programs and data are available on my web site. All errors are my own responsibility. 


\section{Liquidity in the Futures Pits: \\ Inferring Market Dynamics from Incomplete Data \\ Abstract}

Motivated by economic models of sequential trade, empirical analyses of market dynamics frequently estimate liquidity as the coefficient of signed order flow in a pricechange regression. This paper implements such an analysis for futures transaction data from pit trading. To deal with the absence of timely bid and ask quotes (which are used to sign trades in most equity-market studies), this paper proposes new techniques based on Markov chain Monte Carlo estimation.

The model is estimated for four representative Chicago Mercantile Exchange contracts. The highest liquidity (lowest order flow coefficient) is found for the S\&P index. Liquidity for the Euro and UK $£$ contracts is somewhat lower. The pork belly contract exhibits the least liquidity.

Keywords: Futures Markets, Liquidity, Gibbs Sampler, MCMC, Markov chain Monte Carlo, Foreign Exchange, Stock Index Futures. JEL Classification: C1, C11, C13, C15, G1, G10 


\section{Introduction}

US futures exchanges utilize a physically convened open outcry trading mechanism that poses particular challenges to the measurement of trading costs, order impacts and other attributes of liquidity. The present perspective, based on sequential trade models of asymmetric information, is very similar to the approach widely used in equity studies. Specifically, quote setters post bid and/or offer quotes, potential traders arrive and buy or sell, and after any trade, quotes are revised. This logic supports dynamic models in which price changes are regressed against order flows that are signed (positively for buyer-initiated and negatively for seller-initiated orders). ${ }^{1}$

These specifications, however, make strong demands on market data. Construction of signed order flow generally requires data for both transactions (price and volume) and quotes (bid and ask). While quote data are commonly available for equity markets, and markets that are organized as electronic limit order books, they are not generally available for open outcry markets. Specifically, bids and offers in futures pits expire (unless hit) virtually instantaneously, and are therefore seldom recorded.

The analysis of futures trading in the present paper is based on a novel econometric approach that facilitates estimation of rich microstructure models from limited data. In this approach, the bid, ask and, most importantly, the direction (sign) of a given trade are viewed as latent, unobserved variables. I sign a trade, or, (more accurately) derive a probability density for the sign of the trade, conditional on the model and all observed data.

This is essentially the modeling perspective of Glosten and Harris (1988). The present analysis generalizes their model in numerous respects, and suggests a new direction in estimation approach. Glosten and Harris use a non-linear state-space,

\footnotetext{
${ }^{1}$ Theoretical analyses include Glosten and Milgrom (1985), Easley and O'Hara (1992a); Easley and O'Hara (1991); Easley and O'Hara (1987); Easley and O'Hara (1992b) and O'Hara (1995). Representative empirical studies include Hasbrouck (1991a); Hasbrouck (1996a); Huang and Stoll (1994); Huang and Stoll (1997) and Madhavan, Richardson, and Roomans (1997).
} 
maximum likelihood approach. This paper implements a Bayesian analysis using a Markov chain Monte Carlo (MCMC) estimator, the Gibbs sampler, which is attractive both analytically and computationally. ${ }^{2}$ Bayesian methods are usually employed to incorporate prior beliefs about parameters. The more compelling motivation for the use of Bayesian methods in the present case, however, lies in the analytical and computational ease with which latent variables (such as the unobserved trade direction) may be incorporated.

The paper presents analyses for the CME pork belly, Euro, UK £ and S\&P 500 index contracts, for two microstructure specifications. The first is a variant of the Roll (1984) model. This is a useful starting point due to its simplicity and the availability of an alternative estimation technique, the (standard) moment approach. The second specification allows for price discreteness, clustering and trade-price impacts. The estimates of this model for the four contracts suggest substantial (and presumably informational) effects of trades on prices, non-informational costs of market-making that are small relative to the tick size, and (for the pork-belly and S\&P contracts) significant price clustering. Taking the price impact coefficient as a summary measure of liquidity, the $\mathrm{S} \& \mathrm{P}$ contract is the most liquid, followed by the two currency contracts, and the pork belly contract is the least liquid.

Excellent prior studies of futures market liquidity are available. Those based on transaction-level data include Laux and Senchack (1992) and Ma, Peterson, and Sears (1992). These analyses employ moment-based estimates of the Roll model. For the present data, moment estimates are significantly higher than the corresponding MCMC estimates. The Roll model does not allow for informational price impacts. Manaster and

\footnotetext{
${ }^{2}$ Bayesian MCMC applications in market microstructure include Hasbrouck (1999b) and Ball and Chordia (2001). The techniques have also been used extensively in the analysis of stochastic volatility models (Shephard (1993); Engle (1994); Jacquier, Polson, and Rossi (1994); Kim, Shephard, and Chib (1998); Jones (2002)). For textbook expositions, see Carlin and Louis (1996), Gamerman (1997), and Kim and Nelson (2000). Other useful introductory materials include: Gilks, Richardson, and Spiegelhalter (1996) (for a concise overview of MCMC techniques), Casella and George (1992) (for the Gibbs sampler) and Chib and Greenberg (1996) (for applications in econometrics).
} 
Mann (1996) and Locke and Venkatesh (1997) use Computerized Trade Reconstruction (CTR) data. These data (which are not publicly available) establish trader identity, permit tracking of trader positions, and so support a range of interesting analyses concerning inventory control. Manaster and Mann also estimate order impacts contingent on class of trader. Identification of a buyer and seller does not, however, establish who initiated the trade (in the sense of the sequential trade models), i.e., which party hit or lifted the bid or ask exposed by the other.

The paper is organized as follows. The next section summarizes trading procedures and some key features of the futures data. The paper then treats a simple and familiar microstructure construct (the Roll (1984) model of the bid-ask spread) from both conventional and modern Bayesian approaches (Section 3). A more comprehensive and realistic model that incorporates asymmetric information, discreteness and clustering is presented in Section 4. Section 5 covers results for the futures contracts. Section 6 discusses extensions. A brief summary concludes the paper in Section 7.

\section{Institutional background and preliminary features of the data}

The Chicago Mercantile Exchange is a major U.S. futures exchange. Their web site (at www.cme.com) provides a comprehensive description of the Exchange, instruments, trading mechanisms and data (including that used in the present study). The trading arrangements at the CME are typical of U.S. futures exchanges. Traders interact face-to-face on the exchange floor. They compete by shouting and signing acceptable price/trade combinations. There is no presumption that a bid or offer is good until explicitly canceled or modified. A trader who wishes to signal ongoing availability of a price may continually repeat a bid or offer. This transience does not, however, invalidate the sequential trade framework, since we are still in a world where the quote setter moves first and the (potential) "market order" trader follows.

An observer on the floor sees bids, offers and trades. In real time, however, offfloor participants must rely on the electronically disseminated tick data. The reported price is the most current trade price. This is updated only when a trade at a new price 
occurs. This differs from the last sale reporting practices in U.S. equities markets, wherein a trade is reported even if it is at the same price as the previous trade. Smith and Whaley (1994) discuss estimators of the Roll bid-ask spread using time and sales data.

The data used in the present study are drawn from the CME's volume-tick files, and consist of time-stamped trade prices and volumes. These data encompass all trades (not just those with nonzero price changes), and thus constitute a record substantially similar to what researchers employ from the U.S. equity market's Consolidated Transaction System. The sample consists of trading data for one month for four representative contracts. The contracts are: pork bellies (an important agricultural commodity); the Euro (the dominant currency contract); the UK $£$ (an actively traded non-EMU currency); and the S\&P 500 index (the dominant stock index contract).

These data are synthesized from tick reports, clearing records and audit information. They are essentially the computerized trade reconstruction (CTR) data used by Manaster and Mann (1996), Ferguson, Mann, and Schneck (1998) and others, with trader identifications suppressed. Because the CTR data are constructed from clearing records, there are not likely to be many spurious or omitted trades. The time stamps assigned to the trades, however, are less certain. The empirical specifications used here derive from the sequential trade models. For present purposes, therefore, errors in time stamps are most serious when they reorder the trades. This concern cannot be summarily dismissed. Current reporting practices, however, are considerably improved over earlier procedures. ${ }^{3}$ Indeterminate time assignments in CTR data generally appear as clustering in the time reports of trades with the CME's fifteen-minute reporting windows. The time reports in this sample are indeed clustered at one- and fifteen-minute intervals. Although discernible, however, the clustering is not highly pronounced. This suggests that time stamps are not being systematically shifted in a large and obvious way.

\footnotetext{
${ }^{3}$ The trade time is generally the time stamp of execution in the pit. This is bracketed by two other time stamps entered by the broker's clerk: a stamp when the order was received from the customer and another when the execution report was received.
} 
Table 1 describes various features of the analyzed contracts. Of particular relevance for the paper are the tick sizes. As a proportion of the contract price, they are often dramatically lower than those commonly encountered in equity markets. A tick of $\$ 1 / 16$ is $0.125 \%$ of a $\$ 50$ stock. This is somewhat greater than that of any of the futures contracts. The standard deviation of the price change measured in ticks, however, is relatively small. This suggests that the tick size is not negligible relative to phenomena of economic interest, and furthermore suggests the importance of modeling discreteness.

Table 1 also describes the scale and timing of the transactions. For sheer pace of trading activity, the S\&P composite contract stands out. It exhibits an average intertransaction time of only five seconds. Trades frequently occurred within the same second. The economic framework of the sequential trade models generally assumes that trade reports are instantaneously disseminated and evaluated. In the S\&P index pit, at least, an individual trader's information set is unlikely to be this current.

This preliminary analysis suggests the following considerations for modeling strategy. First, motivated by the economic sequential trade models, it seems desirable (as in the equity market studies) to allow for trade-driven price impacts of both a transient (cost-related) and permanent (informational) nature. The results of this section suggest that in addition, discreteness is important because the tick size is generally on the same scale as intertransaction volatility.

\section{The Bayesian approach to estimation of microstructure models}

This section discusses the essentials of modern Bayesian estimation in the context of market microstructure analyses. By virtue of its simplicity and familiarity, the Roll (1984) model of the bid-ask spread is a convenient starting point. The discussion presents the model, classical and Bayesian approaches to estimation, and the application to the futures market data.

\section{a. The basic Roll model}

A variant of the Roll model is as follows. Let the efficient price be denoted $M_{t}$. Its $\operatorname{logarithm} m_{t}=\log \left(M_{t}\right)$ is assumed to evolve as a normal random walk: 


$$
m_{t}=m_{t-1}+u_{t} \text { where the } u_{t} \text { are i.i.d. } N\left(0, \sigma_{u}^{2}\right) .
$$

The term "efficient price" is used here in the sense common to the sequential trade models, i.e., the expected terminal value of the security conditional on all public information (including the trade history). The $u_{t}$ reflect new public information. The (log) bid and ask prices are given as

$$
\begin{aligned}
& b_{t}=m_{t}-c \\
& a_{t}=m_{t}+c
\end{aligned}
$$

where $c$ is the nonnegative half-spread. In this framework, $c$ is the execution cost paid by the active buyer or seller, presently reported by equity markets in conformance with SEC rule 11ac1-5 (U.S. Securities and Exchange Commission (2001)). Under additional assumptions (absence of asymmetric information, fixed trading costs, competition among dealers, etc.), $c$ will be equal to the cost of market making, but this interpretation is not necessary to motivate the model.

The direction of the incoming order is given by the Bernoulli random variable $q_{t} \in\{-1,+1\}$, where -1 indicates an order to sell (to the quote-setter) and +1 indicates an order to buy (from the quote-setter). Buys and sells are assumed equally probable. In the standard implementation, $q_{t}$ is assumed independent of $\Delta m_{t}=u_{t}$, i.e., that the direction of the trade is independent of the efficient price movement. This assumption is restrictive because it rules out the asymmetric information aspects of the sequential trade models. It is relaxed in later sections. Depending on $q_{t}$, the $(\log )$ transaction price is either at the bid or the ask:

$$
p_{t}=\left\{\begin{array}{l}
b_{t} \text { if } q_{t}=-1 \\
a_{t} \text { if } q_{t}=+1
\end{array}\right.
$$

The model parameters are $c$ and $\sigma_{u}$. Inference is based on a time series sample of trade prices $p=\left\{p_{1}, p_{2}, \ldots, p_{T}\right\}$. The following sections describe method-of-moments classical and Bayesian approaches to estimation. In the present application, both approaches assume that the dynamic model given in this section is the correct one. Although both approaches can accommodate model uncertainty, the present treatment does not develop this aspect of the problem. 


\section{b. The conventional (method of moments) approach}

The model implies

$$
\Delta p_{t}=m_{t}+c q_{t}-\left(m_{t-1}+c q_{t-1}\right)=c \Delta q_{t}+u_{t},
$$

from which it follows that:

$$
\begin{aligned}
\operatorname{Var}\left(\Delta p_{t}\right) & =\sigma_{u}^{2}+2 c^{2} \\
\operatorname{Cov}\left(\Delta p_{t}, \Delta p_{t-1}\right) & =-c^{2}
\end{aligned}
$$

The corresponding sample estimates for the variance and autocovariance imply estimates for $\sigma_{u}$ and $c$ that possess all the usual properties of GMM estimators, including consistency and asymptotic normality. Moment estimation for this model is relatively easy to implement and often satisfactory.

\section{c. Bayesian estimation}

The Bayesian perspective departs most fundamentally from classical approaches in that parameters are viewed as random variables. This randomness reflects the statistician's uncertainty, however, and most emphatically does not imply that parameters are stochastic within a data sample. Thus in the present model neither $c$ nor $\sigma_{u}$ is timevarying. The prior distributions impound the initial parameter uncertainty. Estimation involves construction of parameter posteriors, which are conditional on the observed data and incorporate all of the information in the observations

Bayesian analyses are often motivated as a means for incorporating prior beliefs, and are often criticized for sensitivity to choice of prior distributions. In the present applications, neither of these points is a major consideration. The parameter priors are essentially uninformative; the posteriors are essentially "data dominated". ${ }^{4}$

\footnotetext{
${ }^{4}$ In one interesting respect the parameter prior is substantive, however. Economic logic dictates $c \geq 0$. The statistical structure of the model actually forces the first-order autocovariance in equation (5) to be nonpositive irrespective of the sign of $c$. In sample data, however, this property is sometimes violated. In his examination of U.S. stock data, for example, Roll finds that autocovariance estimates based on 21 daily returns are positive roughly half the time. Harris (1990b) notes that positive sample autocovariances will often arise even if the model is correctly specified. Our conviction that $c \geq 0$ is a prior belief, and as such is most naturally incorporated in a Bayesian framework.
} 
The more important motivation for a Bayesian approach here derives from the power of modern Bayesian techniques for accommodating latent (unobserved) data. Latent data in the Roll model include bids, asks and trade direction indicators. These quantities are not artificial features of a statistical model, but are instead constructs that are economically and structurally meaningful. These latent data are suppressed in the GMM estimation. GMM procedures are also limited by the difficulty of computing moments in richer and more realistic models.

The Roll model has two parameters ( $c$ and $\sigma_{u}$ ) and $T$ latent data values: $q=\left\{q_{1}, q_{2}, \ldots, q_{T}\right\}$. The full posterior over parameters and latent data is summarized by the distribution function $F\left(c, \sigma_{u}, q \mid p\right)$. There is here (and generally) no tractable closedform representation for this function. Instead, it is characterized by simulation, using techniques that do not require a closed-form representation.

Most of the simulations used in the present paper are Gibbs samplers. The Gibbs sampler is an iterative procedure. An iteration is generally termed a "sweep". Initially, i.e., notationally at the end of sweep $j=0$, the parameters and latent data are set to any values (subject only to feasibility). Denote these initial values $\left\{c^{(0)}, \sigma_{u}^{(0)}, q^{(0)}\right\}$. The steps in the first sweep $(j=1)$ are:

1. Draw $c^{(1)}$ from $f\left(c \mid \sigma_{u}^{(0)}, q^{(0)}, p\right)$

2. Draw $\sigma_{u}^{(1)}$ from $f\left(\sigma_{u} \mid c^{(1)}, q^{(0)}, p\right)$

3. Draw $q^{(1)}$ from $f\left(q \mid c^{(1)}, \sigma_{u}^{(1)}, p\right)$

Note that all draws are from "full conditional distributions". That is, all parameters and latent data except for the component being drawn are taken as given. The next iteration starts with a draw of $c^{(2)}$ conditional on $\sigma_{u}^{(1)}, q^{(1)}$ and $p$. Repeating this $n$ times, we generate a sequence of draws $\left\{c^{j}, \sigma_{u}^{2, j}, q^{j}\right\}$ for $j=1, \ldots, n$. The Gibbs principle ensures that the limiting distribution of the $n$th draw $($ as $n \rightarrow \infty)$ is $F\left(c, \sigma_{u}, q \mid p\right)$, the desired posterior. From an estimation perspective, the limiting draw for any parameter is distributed in accordance with the corresponding marginal posterior. For example, the limiting density of $c^{(n)}$ is $f(c \mid p)$. 
How large must $n$ be? The Gibbs sampler is essentially a Markov chain, and the desired distribution is its limiting distribution. Intuitively, $n$ must be sufficiently large that dependence on the initial conditions (the starting values) becomes vanishingly small. Furthermore, the cyclic nature of the Gibbs sampler generally means that successive draws are dependent. Fortunately, inference does not generally require independent draws. The $c^{(j)}$ draws, for example, may be viewed as dependent draws from the parameter posterior. Population parameters of the posterior may be estimated using the methods of standard time series analysis. For example, the sample mean of the $c^{(j)}$ is a consistent estimate of $E[c \mid p]$; the sample variance is a consistent estimate of $\operatorname{Var}[c \mid p]$, and so on. ${ }^{5}$

The number of draws is limited by computational resources, not sample size. Furthermore, the limiting distribution (as the number of draws increases) is the exact small-sample posterior for the given data sample. Finally, suppose that we are interested in some continuous function of the model parameters, $g\left(c, \sigma_{u}\right)$. For a set of parameter draws, $\left\{c^{(j)}, \sigma_{u}^{(j)}: j=1, \ldots, n\right\}$, the corresponding sequence $\left\{g\left(c^{(j)}, \sigma_{u}^{(j)}\right): j=1, \ldots, n\right\}$ generally has as its limiting distribution the posterior for $g\left(c, \sigma_{u}\right)$. Transformations of model parameters are often used in this paper to facilitate presentation and discussion of results.

The power of Bayesian analysis using the Gibbs sampler derives from the fact that the full conditional distributions are often tractable. In the present case, for example, conditional on $q$, eq. (4) can be treated as a simple regression specification in which $c$ and $\sigma_{u}$ are the coefficient and residual dispersion, respectively. The normal linear regression model is a standard Bayesian estimation problem, and it is common practice to use a

\footnotetext{
${ }^{5}$ Of course, determination of the precision of these estimates must take into account the observational dependencies. The standard error of the mean estimate, for example, can be computed using that standard spectral correction described in Hamilton (1994).
} 
normal prior for the coefficients and an inverted gamma prior for the residual dispersion. ${ }^{6}$ For $q$, the model suggests obvious priors, specifically $q_{t}= \pm 1$ with equal probability.

\section{d. Application to the futures market data}

The model discussed above was estimated for the four representative CME contracts using 10,000 draws of the Gibbs sampler. The computational details of the draws are described in the appendix to this paper.

The model parameters are $c$ and $\sigma_{u}$. To expedite the discussion, the exhibits summarize $c, \sigma_{u}$ and a level version of the cost parameter $C \equiv c \times \bar{P}$, where $\bar{P}$ is the average price level (in ticks). Figure 1 depicts histograms of the parameter draws, which represent (in the limit) the parameter posteriors. These are visually well-defined, unimodal and concentrated. Table 2 reports summary statistics (labeled "Bayes, $q$ simulated").

To place the estimates in perspective, note that we can impute an approximate annualized volatility for the contracts as $\sigma_{u} \times \sqrt{(250 \text { trading days }) \times(\text { Avg. dailytrades })}$. This is an intraday estimate; it excludes overnight price changes. The pork belly contract averaged 194 trades (Table 1), implying an annualized value of 45\%. Values for the Euro, UK $£$ and S\&P are $6 \%, 5 \%$ and $27 \%$. The $C$ estimates are uniformly less than the tick size, which motivates a more thorough modeling of discreteness.

By way of comparison, Table 2 also reports conventional moment estimates of the model. For the volatility parameter, the Bayesian and moment estimates are fairly close (with the exception of the S\&P contract. In the case of the cost parameters ( $c$ and $C$ ), however, the moment estimates are substantially higher than the Bayesian estimates.

The estimates can be reconciled by considering the different ways in which the two approaches use the sample data. Eq. (5) implies $c=\sqrt{-\operatorname{Cov}\left(\Delta p_{t}, \Delta p_{t-1}\right)}$. In a sense,

\footnotetext{
${ }^{6}$ For the analyses reported in the paper, the prior for $c$ was $N\left(\mu, \sigma^{2}\right)$ with $\mu=0$ and $\sigma^{2}=10^{6}$, restricted to the positive domain; the prior for $\sigma_{u}^{2}$ was inverted gamma with $\alpha=\beta=10^{-12}$.
} 
therefore, the moment approach attributes the entire price-change autocovariance to cost. More generally, though, from eq. (4),

$$
\operatorname{Cov}\left(\Delta p_{t}, \Delta p_{t-1}\right)=E u_{t} u_{t-1}+c\left(E u_{t} \Delta q_{t-1}+E u_{t-1} \Delta q_{t}\right)+c^{2} E \Delta q_{t} \Delta q_{t-1}
$$

The structural independence assumptions imply that all of the terms on the r.h.s. vanish, except for the last (which is equal to -1). The Bayesian approach uses the independence assumptions in deriving the simulation densities, but independence is not imposed on the simulated $u$ and $q$ processes. Most importantly, the sample estimates of $E u_{t} u_{t-1}$ for the simulated values are consistently negative, and the magnitudes can essentially explain the inflation of the moment estimates relative to the Bayesian estimates. ${ }^{7}$ That the estimates of $E u_{t} u_{t-1}$ are non-zero can be viewed as a small-sample effect that would presumably vanish in a large sample. From this perspective, the Bayesian estimates are likely to be superior because the simulated posteriors are exact small sample distributions.

\section{e. Further perspectives on signing trades}

Given the importance attached by the sequential trade models to order direction, it is not surprising that this arises as a perennial concern in microstructure modeling. In the NYSE's unusually-detailed TORQ dataset (Hasbrouck (1992); Hasbrouck (1996b)), it is possible to associate many trades with the actual underlying orders. More commonly, however, trade direction is inferred from related price data. As noted in the introduction, the usual practice is to sign trades by reference to the prevailing quotes (see Hasbrouck and Ho (1987), Hasbrouck (1988), Lee and Ready (1991) and Odders-White (1997)).

In the absence of quote data, one plausible alternative procedure involves assigning trade direction based on a tick test. That is, $q_{t}=+1$ if the price change is an uptick or zero-uptick; $q_{t}=-1$ on a downtick or zero-downtick. The limitations of this

\footnotetext{
${ }^{7}$ In the case of the pork belly contract, for example, the estimate for $\operatorname{Corr}\left(u_{t}, u_{t-1}\right)=-0.038$. Using the Bayesian estimate for $\sigma_{u}^{2}=4.1 \times 10^{-6}$, the implied $E u_{t} u_{t-1}=-1.56 \times 10^{-7}$. Together with the sample estimate $E \Delta p_{t} \Delta p_{t-1}=-2.4 \times 10^{-7}$ and the maintained assumption that $E u_{t} q_{t}=E u_{t} q_{t-1}=0$, eq. (6) implies $c=2.9 \times 10^{-4}$, which is close to the Bayesian estimate $\left(2.52 \times 10^{-4}\right)$.
} 
procedure can be illustrated in a Bayesian framework by fixing the $q_{t}$ at the values implied by the tick rule, and drawing $c$ and $\sigma_{u}$ in the usual fashion. The resulting posterior means (labeled "Bayes, $q$ fixed" in Table 2) differ in some respects from the full (" $q$ simulated") results. In particular, the " $q$ fixed" estimates for the cost parameters of the pork belly and S\&P contracts are much higher than the full Bayesian (or moment) estimates. This is a reflection of the fact that signing-by-tick attributes too much of a given price change to the direction of the trade. ${ }^{8}$

From an econometric perspective, the tick rule is improper because it induces correlation between measurement errors in $q_{t}$ and the model disturbance. Nevertheless, we seem to be drawing inferences about trade direction in the Bayesian analysis that are very similar. A pattern of successive price upticks, for example, will be viewed as a procession of "buy" orders. It might therefore appear that the present analysis falls to the same objections as the proposed naïve one.

There are, however, two crucial differences. First, the present procedure does not assign to a trade a single direction that is used in all subsequent computations. Instead, it imputes a probability density over both (buy and sell) alternatives. In this sense, the procedure explicitly models the measurement error (uncertainty) concerning trade direction. In the second place, the trade directions and model parameters are estimated jointly. This essentially allows uncertainty about model parameters to affect uncertainty about trade direction. We are still, of course, assuming that the model is correctly specified. But we do not assume "full knowledge" (i.e., correct parameter estimates) of the model in the process of assigning trade direction.

\section{Extensions}

The simplicity of the Roll model makes it appropriate for exposition and comparative analysis. Bayesian MCMC approaches readily generalize, however, to more realistic models. This section describes such a richer model.

\footnotetext{
${ }^{8}$ I am indebted to Ken Kavajecz for suggesting this illustration.
} 


\section{a. Trade effects on the efficient price}

The basic model described in the last section assumes that the innovation to the efficient price is independent of the direction of the incoming order, i.e., that the quote setter infers nothing from this order. This is highly restrictive. An essential characteristic of the sequential trade models is the possibility that the incoming order signals the trader's private information, and that the quote setter will use this signal in updating her bid and ask. In lieu of eq. (1), therefore, the evolution of the efficient price might be specified as:

$$
m_{t}=m_{t-1}+\sum_{j=0}^{J} q_{t-j} \lambda_{j}+u_{t}
$$

The $\lambda_{j}$ are impact coefficients (generally positive), and the summation allows for lagged effects. The data in the present study contain trade volumes, and we therefore employ the somewhat broader specification:

$$
\Delta m_{t}=\sum_{j=0}^{J} q_{t-j} \lambda_{j} v_{t-j}+u_{t}
$$

Here, $v_{t}=\left[\begin{array}{ll}1 & \sqrt{\text { Volume }_{t}}\end{array}\right]^{\prime}$ and $\lambda_{j}$ is a $(1 \times 2)$ coefficient vector. This allows for an intercept and concavity in the trade impact. The estimations in this paper use $J=5$. Note that if eq. (7) is used in lieu of eq. (1), the timing convention that the bid and ask quotes are set with respect to $m_{t}$ implies that the cost parameter $c$ does not impound asymmetric information costs.

\section{b. Discreteness}

In the models considered to this point, bids, asks and transaction prices are considered to be continuous random variables. In fact, virtually all markets constrain the support of these quotes to a discrete lattice defined as integer multiples of the "tick" or "pip". The tick size is of economic interest because it is related to the cost of achieving time priority, and therefore to the supply of liquidity (Harris (1997a); Harris (1997b)). From a data-modeling perspective, the tick size is important because it is often (and in the present application) similar in magnitude to the spread and short-term price movements. 
Harris (1990a) suggests a latent-variable model of rounded transaction prices. Hasbrouck (1999a) surveys this and other approaches, and proposes the model used below. Specifically:

$$
\begin{aligned}
& B_{t}=\text { Floor }\left[M_{t}-C\right] \\
& A_{t}=\text { Ceiling }\left[M_{t}+C\right]
\end{aligned}
$$

where $B_{t}$ and $A_{t}$ are the level bid and ask and $M_{t}=\exp \left(m_{t}\right)$. Floor[.] and Ceiling [.] round their arguments asymmetrically, down and up (respectively) to the next grid point. The data are scaled so that the tick size is unity. Quote discreteness in the model (and in reality) is imposed on the level prices. The cost parameter $C$ is now stated in level terms and is assumed to be nonnegative. In the Roll model, this parameter is interpreted as the execution cost paid by the initiator of the trade. It is more natural in the present specification to view $C$ as the non-informational cost of market-making, i.e. a cost borne by the liquidity supplier. The asymmetric rounding ensures that this cost is covered on each trade. The mapping to the observed prices is:

$$
P_{t}=\left\{\begin{array}{l}
A_{t} \text { if } q_{t}=+1 \\
B_{t} \text { if } q_{t}=-1
\end{array}\right.
$$

\section{c. Clustering}

A phenomenon closely related to discreteness is clustering, the tendency of trades (and presumably quotes) to cluster on "natural" multiples of the minimum tick. The futures prices in the sample sometimes exhibit pronounced clustering. To see this, note that with uniformly distributed prices rounded to the nearest tick, the proportion of prices we would expect to see lying on a $\kappa$-multiple of the tick size is $1 / \kappa$. If the actual proportion in a sample is $f_{\kappa}$ then the excessive clustering (actual less expectation) is $f_{\kappa}^{C}=f_{\kappa}-(1 / \kappa)$. Table 3 reports clustering frequency percentages for the sample contracts. Clustering is most extreme (on $\kappa=2$ ) in the pork belly contract. There is modest clustering on $\kappa=5$ for the $\mathrm{S} \& \mathrm{P}$ contract, while the currency prices are not strikingly clustered.

Economic explanations for clustering vary. Harris (1994); Harris (1991) suggest that negotiating parties may adopt a supra-minimum tick convention as a device for 
reducing the number of rounds of bargaining. It is also suggested, however, that when there are barriers to entry in the provision of liquidity services, clustering may serve as an implicit collusive coordination mechanism (Kandel and Marx (1997) and Dutta and Madhavan (1997)). This has been most strongly alleged for the Nasdaq dealer market prior to the reforms in the mid 1990s. ${ }^{9}$

Hasbrouck (1999b) suggests that quote clustering be attributed to an implicit effective tick. The effective tick, denoted $K_{t}$, is a natural multiple of the minimum tick that arises as a trading convention or from individual preference. Clustering is imposed on the (unobserved) bid and ask quotes by using generalized rounding functions:

$$
\begin{aligned}
B_{t} & =\text { Floor }\left[M_{t}-C, K_{t}\right] \\
A_{t} & =\text { Ceiling }\left[M_{t}+C, K_{t}\right]
\end{aligned}
$$

where $K_{t}$ denotes the tick-multiple to which rounding will occur. In economic terms, $K_{t}$ is the implicit tick size. (For example, $K_{t}=2$ implies rounding to even numbers.) While $K_{t}$ might be modeled in a very general fashion, the specifications estimated here will allow for only two possible values: one (that is, the regular tick increment) and $\kappa$, a single dominant multiple. As in Hasbrouck (1999b), it is convenient to assume an i.i.d. Bernoulli distribution:

$$
K_{t}=\left\{\begin{array}{l}
1, \text { w. prob. }(1-k) \\
\kappa, \text { w. prob. } k
\end{array}\right.
$$

The Bernoulli probability parameter $k$ may be interpreted as the clustering intensity. It is distinct from the proportion of prices that occur on $\kappa$-tick multiples because some of these occurrences would arise with simple (unclustered) rounding. The prior for $k$ was $\operatorname{Beta}(a, b)$ with $a=b=1 / 2$, i.e., uniform between zero and one.

\section{d. Summary}

The full model consists of efficient price dynamics given in equation (8); the implicit tick specification (12); the rounding transformation for the bid and ask quotes

\footnotetext{
${ }^{9}$ The literature on clustering at Nasdaq is large. Key references include Christie, Harris, and Schultz (1994); Schwert (1997).
} 
(11); and the transaction price realization (10). The observed data are the trade prices and volumes $\left\{P_{t}\right.$, volume $\left._{t}\right\}$. The latent data are the efficient prices, trade direction indicators and implicit tick sizes $\left\{m_{t}, q_{t}, K_{t}\right\}$. The model parameters are $\left\{\sigma_{u}^{2}, C, k, \lambda_{0}, \ldots, \lambda_{J}\right\}$. The clustering statistics reported above suggest taking $\kappa=2$ for the pork belly contract ("clustering on even prices") and $\kappa=5$ for the S\&P contract. The currency contract prices are not markedly clustered, but for the sake of estimating all specifications in parallel for all contracts, I allow $\kappa=5$.

From a structural economic perspective, the components of the model strongly resemble other pre-existing empirical formulations of the sequential trade models. The specification of the efficient price and related trade impacts (8) is similar to those used in Glosten and Harris (1988), George, Kaul, and Nimalendran (1991); Hasbrouck (1991b), Huang and Stoll (1994); Huang and Stoll (1997) and Madhavan, Richardson, and Roomans (1997), among others. Except in the framework of Glosten and Harris, however, the transaction price is a linear function of other structural variables. In the present model, the mapping from efficient to transaction prices is mediated by the nonlinear and stochastic rounding transformations that generate bids and asks.

\section{Application to the futures data}

The comprehensive model described in the last section was estimated for the four representative contracts.

\section{a. Parameter estimates.}

Table 4 reports parameter estimates. From an economic viewpoint, the most interesting are those that asses trade impacts (the $\lambda \mathrm{s}$ ). For brevity, only the sums are reported. The sums of $\lambda_{\text {Intercept }}$ and $\lambda_{\text {Slope }}$ are positive, with the exception of $\lambda_{\text {Slope }}$ for the UK $£$. The estimated trade effects may be characterized in two ways. First, Figure 2 graphs the implied price impact functions. The vertical scale is approximately the proportional price change in basis points associated with a purchase of a given number of contracts. This is the cumulative impact (i.e., through lag 5), although the changes for all contracts were substantially complete after the second period. For a trade of a given size, 
the price impact is relatively large for the pork belly contract, but low for the currency and S\&P contracts.

Secondly, recall that the efficient price dynamics are the given by the linear specification in eq.(8). The coefficient of determination in this specification is a useful summary measure of the relative importance of trades in explaining (efficient) price volatility. This coefficient is denoted $R_{\Delta m}^{2}$, Trades , by analogy with the usual regression $R^{2}$. The logic of the sequential trade models suggests this is a summary measure of information asymmetry (Hasbrouck (1991b)). Table 4 reports the estimates. They are relatively high for the pork belly contract (61\%), the Euro (53\%), and the UK $£(67 \%)$, but lower for the S\&P (8\%). To put this in context, a corresponding value for an NYSE equity might be around 30-40\% percent (Hasbrouck (1991b)).

These interpretations are contingent on the assumption that the estimated trade impacts are permanent. In this context, it must be admitted that the models are short-run specifications. They may not detect reversals or reversions that occur over intervals longer than the five lagged trades, as might be implied by inventory control. Reversions would, of course, imply that the estimated permanent impacts are overstated.

Estimates of cost parameter $C$ are dramatically lower than the corresponding estimates for the basic Roll model (cf. Table 2). In fact, graphs of the $C$ posteriors for the present model (not shown) suggest that the bulk of the probability mass was quite near zero. Alternative estimates (not shown) indicate that for the present model, when $C$ is constrained to zero, estimates of other parameters are little affected.

These findings admit a simple explanation. In the present model, bid and ask quotes arise from rounding transformations applied to latent continuous variables (including $C$ ). That the $C$ posteriors are massed near zero suggests that the rounding transformations suffice to account for the observed data. Alternatively, it appears that $C$ is so small relative to the tick size, that it cannot be well-characterized by the relatively coarse price data. 
The estimates of clustering intensity parameter $k$ are generally consistent with the relative clustering propensities described in Table 3: high for the pork belly and S\&P contracts; low for the currency contracts.

\section{b. Discussion}

The economic models of sequential trade identify permanent trade price impacts with asymmetric information, private information that can be revealed in the price only through trade. From this perspective, it is perhaps not surprising that a significant proportion of volatility in the pork belly market originates from trades. There are, for this contract, few alternative sources of price discovery.

In currency markets, however, the prevailing view ascribes a distinctly subsidiary role for futures trading. ${ }^{10}$ Lyons (2001) comments, "In FX ... the futures market is much smaller than the spot market; it is unlikely that a significant share of price determination occurs there." The futures contract is often supposed to serve as a hedging and speculation vehicle for participants too small to obtain easy access to the larger market. One would therefore expect currency futures prices to follow passively the path established in the interbank market. From this perspective, the high explanatory power of trades is surprising.

The interbank market, however, is a low-transparency venue. The public record of the interbank market is limited to indicative (nonfirm) bids and offers. Trades that occur on the electronic book systems are visible only to other subscribers (essentially the large intermarket banks themselves). Neither trades occurring directly between two participants nor those mediated by brokers are publicly reported. The usefulness of the Reuters indicative quotes as a timely, high-resolution signal for futures price discovery appears doubtful. It seems reasonable to hypothesize that some trades in the futures market are driven by information that may have originated in the interbank market (such as knowledge of a recent interbank trade), and is "private" in the sense of not being widely

\footnotetext{
${ }^{10}$ Recent microstructure studies of the latter include Lyons (1997); Lyons (1995); Goodhart, Ito, and Payne (1996) and Evans (2002).
} 
reported. Although remaining (in a sense) a subsidiary player in this market, the futures market may be serving as the primary forum of public price discovery.

For the $\mathrm{S} \& \mathrm{P}$ contract, the quantity-impact functions (Figure 2) and the $R_{\Delta m, \text { trades }}^{2}$ values (Table 4) suggest a role for trades that is extremely, perhaps implausibly, low. While the cash market exists as a meaningful alternative for price discovery, the stock index futures market is customarily viewed as originating the primary signals of common factor equity movements. Both the numerous studies documenting index price leadership in the futures markets, and the studies that address regulatory concerns support this view.

In considering model adequacy for this contract, it is noteworthy that the index futures market is substantially more active than the others. Section 2 noted an average intertrade time of five seconds and raised the possibility of associated informational delays. In principle, estimation is not affected by real-time frequency of trading. However, high activity undoubtedly places stress on the reporting and data collection systems. This increases the likelihood that the reported transactions are not correctly sequenced. The noise introduced by sequencing errors might well attenuate the estimated trade impacts.

Finally, trade price impact studies in equity markets generally find asymmetries between purchases and sales with purchases having the larger impact (Holthausen, Leftwich, and Mayers (1987); Holthausen, Leftwich, and Mayers (1990); Chan and Lakonishok (1993); Chan and Lakonishok (1995)). This possibility suggests generalizing eq. (8) to:

$$
\Delta m_{t}=\sum_{j=0}^{J} q_{t-j}^{+} \lambda_{j}^{+} v_{t-j}+\sum_{j=0}^{J} q_{t-j}^{-} \lambda_{j}^{-} v_{t-j}+u_{t}
$$

where $q_{t}^{+}=\operatorname{Max}\left(0, q_{t}\right)$ and $q_{t}^{-}=\operatorname{Min}\left(0, q_{t}\right)$ are the positive and negative parts of $q_{t}$. To investigate this specification without incurring the complexity of a full Gibbs sampler, eq. (13) was estimated using the $q_{t}$ generated in the estimation of the symmetric model. The distributions of the buy and sell impact coefficients $\left(\lambda_{j}^{+}\right.$and $\left.\lambda_{j}^{-}\right)$were found to be very similar. 


\section{Other extensions and modifications}

The MCMC approach is sufficiently general to accommodate numerous useful generalizations of the present models, including random costs of quote exposure, stochastic volatility, and stochastic liquidity. Such extensions are facilitated by the modularity of the MCMC framework. The basic building block is a draw (simulation) from a "full conditional" density. In such a simulation, with the exception of the particular variable being drawn, all other latent data and parameters, including those that are stochastic in the full model specification, are provisionally taken as fixed.

A model may offer great economic appeal and even simplicity in its conditional distributions, however, and still severely tax the ability of the data to meaningfully identify the parameters. Estimates of costs and trade impacts in the present family of models, for example, are sensitive to how discreteness and clustering are modeled.

As a further example, it is sensible to generalize the Roll model to allow stochastic costs of quote exposure, i.e. to replace the time-invariant parameter $c$ with a stochastic process $\left\{c_{t}\right\}$. It is certainly possible to reliably estimate such models when the bid and ask quotes are observed, as in U.S. equities (Hasbrouck (1999a)) or foreign exchange (Hasbrouck (1999b)).

Estimation is more difficult, however, when inference is attempted solely from transaction prices. With the present data, for example, I attempted to estimate models under the assumption that $\log \left(C_{t}\right) \stackrel{\text { i.i.d. }}{\sim} N\left(\mu_{c}, \sigma_{c}^{2}\right)$. The Gibbs samplers exhibited poor mixing and convergence properties. This is perhaps not surprising. As in the basic Roll model, the only nonzero second-order moments of price changes are the variance and first-order autocovariance. These are obviously insufficient to identify the three parameters $\left\{\mu_{c}, \sigma_{c}^{2}, \sigma_{u}^{2}\right\}$. In fact, identification requires fourth moments of price changes, and, for determining distributional properties, eighth moments. Even when these moments exist, sampling may be problematic. ${ }^{11}$

\footnotetext{
${ }^{11}$ Alternatively, Ball and Chordia (2001) estimate a modification of a spread model suggested in Hasbrouck (1999a) that allows for autoregressive dependence in $C_{t}$. The
} 


\section{Conclusions}

This paper proposes and implements powerful strategies to estimate empirical microstructure models when the data consist of trade prices or alternatively, prices and volumes. The specifications apply the signed return/signed order flow regressions common in equity market studies to a setting in which there is no record of the quotes, and therefore no straightforward way to sign trades as buyer- or seller-initiated. The analysis is made possible by recent advances in Markov chain Monte Carlo estimation (MCMC), which simplify inference in dynamic latent (unobserved) variable models. In the present applications, the latent data are the trade signs. These are simulated, conditional on the structure of the model and the observed data. The techniques are Bayesian, but except in one respect (noted below) the priors used in the analyses are not informative.

The paper presents an analysis of four representative futures contracts traded on the Chicago Mercantile Exchange: pork bellies, the S\&P Composite Index and two currency contracts (the Euro and the UK £). The first application involves a variant of the Roll (1984) model of transaction prices subject to bid-ask effects. For the data samples in this paper, for comparison purposes, this model can also be estimated using the standard moment-based approaches. For all contracts, both MCMC and moment approaches yield similar estimates of the long-run volatility. The MCMC estimates of the effective execution costs (the half-spread), however, are substantially smaller than the corresponding moment estimates. This appears to reflect the fact that the moment approach attributes all of the sample price-change autocovariance to the execution cost. The MCMC approach does not force this attribution. As there are no direct observations of the parameter, it is not possible to say for certain which estimate is closer to the truth. It is worth noting, however, that if the model is correctly specified, the MCMC parameter posteriors are exact small-sample distributions. The moment estimates in contrast are valid only asymptotically, and may therefore be less robust in finite samples.

smoothing in this model appears to greatly enhance identification and performance of the Gibbs sampler. 
The only respect in which the MCMC parameter priors are informative is that the execution cost is constrained to be positive. This property is economically sensible.

Furthermore, the ability to estimate the Roll model subject to this requirement extends the usefulness of this model to the many data samples in which moment estimates are infeasible. In monthly samples of daily stock return data, for example, only about half the samples yield feasible estimates. Thus, the MCMC approach shows promise in establishing execution cost estimates in historical and international security datasets which contain only transaction prices. Hasbrouck (2003) shows that Gibbs estimates of execution cost based on daily CRSP data are highly correlated with estimates derived from detailed trade and quote (NYSE TAQ) data from 1993 to 2001. Furthermore, the Gibbs cost estimates constructed for the full daily CRSP sample (1962 onwards) are positively related to excess returns.

The full specification estimated in this paper is a structural model of bid and ask quotes and trades that incorporates discreteness, clustering and asymmetric information. In application to the four contracts, several significant results emerge.

First, the estimates imply statistically and economically significant effects of signed orders on prices for the pork belly, Euro and pound contracts. If these order impacts are permanent, the estimates suggest that roughly half of the long-term price volatility in these contracts is attributable to trades, and by implication, the private information signals contained in these trades. The present specifications are short term, however, covering only five lagged trades. They lack the power to detect reversions or reversals in the price impacts extending over significantly longer intervals, as might be implied by inventory effects. For the S\&P contract, estimated order impacts are low, and less than ten percent of the volatility can be attributed to trades.

This first result is broadly consistent with empirical analyses of equities (which are based on richer data records). Taking the order impact coefficients as measures of liquidity, the S\&P contract is the most liquid. An order of roughly 50 contracts (corresponding to roughly $\$ 16.5$ Million in underlying value) moves the price by only about one basis point. The pork belly contract is the least liquid: one contract (about 
$\$ 23,000$ in underlying value) moves the price by about ten basis points. The currency contracts lie between these extremes.

Second, the non-informational costs of market making are substantially smaller than the tick size (price increment). The relative coarseness of the price data precludes precise estimation.

Third, the estimates imply price clustering (affinity for natural multiples of the minimum tick) that is very strong for the pork belly contract, moderate for the S\&P contract and negligible for the currency contracts. It is not determined whether this clustering arises from negotiation-cost minimization or market power of floor traders.

The relatively high liquidity found for the $\mathrm{S} \& \mathrm{P}$ contract is unsurprising. This market is widely acknowledged to be extremely active. An index, furthermore, diversifies the private information found in the individual components (Subrahmanyam (1991)). The low estimated trade impacts found in the present analysis, however, might also result from incorrect trade sequencing, due to a reporting system that is taxed by the rapid pace of activity.

For the currency contracts, the strong contribution of trades to price volatility suggests that that futures trading contributes significantly to the price discovery process. This runs counter to the conventional wisdom that price determination in foreign exchange occurs in the interbank spot/forward market. Transparency in the interbank market, however, is low. Given that interbank trades are not reported, it is perhaps not surprising that the publicly-reported (though smaller) futures trades play a substantial role in price discovery.

Finally, the present models analyses by no means exploit the full potential of the approach. The structure of a Gibbs sampler is essentially modular, and adding a new feature often involves little more than adding a new step in each sweep. Extensions that might be desirable in some applications would include stochastic volatility and multiple securities. Furthermore, the present techniques are potentially applicable not only to security markets, but also to markets for nonfinancial assets, products and services. 


\section{References}

Ball, C.A., and T. Chordia. "True Spreads and Equilibrium Prices." Journal of Finance, $56(2001), 1801-35$.

Carlin, B. P., and T. A. Louis. Bayes and Empirical Bayes Methods for Data Analysis. London: Chapman and Hall (1996).

Casella, G., and E.I. George. "Explaining the Gibbs Sampler." The American Statistician, 46 (1992), 167-90.

Chan, J., and J. Lakonishok. "Institutional Trades and Intraday Trade Price Behavior." Journal of Financial Economics, 33 (1993), 173-99.

Chan, J., and J. Lakonishok. "The Behavior of Stock Prices Around Institutional Trades." Journal of Finance, 50 (1995), 1147-74.

Chib, S., and E. Greenberg. "Markov Chain Monte Carlo Simulation Methods in Econometrics." Econometric Theory, 12 (1996), 409-31.

Christie, W.G., J.H. Harris, and P.H. Schultz. "Why Did NASDAQ Market Makers Stop Avoiding Odd-Eighth Quotes?" Journal of Finance, 49 (1994), 1841-60.

Dutta, P.K., and A.M. Madhavan. "Competition and Collusion in Dealer Markets." Journal of Finance, 52 (1997), 245-76.

Easley, D., and M. O'Hara. "Price, Trade Size, and Information in Securities Markets." Journal of Financial Economics , 19 (1987), 69-90.

Easley, D., and M. O'Hara. "Order Form and Information in Securities Markets." Journal of Finance, 46 (1991), 905-27.

Easley, D., and M. O'Hara. "Adverse Selection and Large Trade Volume: The 
Implications for Market Efficiency." Journal of Financial and Quantitative Analysis, 27 (1992a), 185-208.

Easley, D., and M. O'Hara. "Time and the Process of Security Price Adjustment." Journal of Finance, 47 (1992b), 576-605.

Engle, R.F. "Bayesian Analysis of Stochastic Volatility Models: Comment." Journal of Business and Economic Statistics, 12 (1994), 395-96.

Evans, M.D.D. "FX Trading and Exchange Rate Dynamics." Journal of Finance, 57 (2002). 2405-2447.

Ferguson, M.F., S.C. Mann, and L.J. Schneck. "Concentrated Trading in the Foreign Exchange Futures Markets: Discretionary Liquidity Trading or Market Closure." Journal of Futures Markets, 18 (1998), 343-62.

Gamerman, D. Markov Chain Monte Carlo. New York: Chapman and Hall (1997).

George, T.J., G. Kaul, and M. Nimalendran. "Estimation of the Bid-Ask Spread and Its Components: a New Approach." Review of Financial Studies, 4 (1991), 623-56.

Gilks, W. R., S. Richardson, and D. J. Spiegelhalter. "Introducing Markov Chain Monte Carlo." in Markov Chain Monte Carlo in Practice, W. R. Gilks, S. Richardson, and D.J. Spiegelhalter, eds. London: Chapman and Hall (1996).

Glosten, L.R., and L.E. Harris. "Estimating the Components of the Bid/Ask Spread." Journal of Financial Economics, 21 (1988), 123-42.

Glosten, L.R., and P.R. Milgrom. "Bid, Ask, and Transaction Prices in a Specialist Market With Heterogeneously Informed Traders." Journal of Financial Economics, 14 (1985), 71-100.

Goodhart, C., T. Ito, and R. Payne. "One Day in June 1993: A Study of the Working of 
the Reuters 2000-2 Electronic Foreign Exchange Trading System." in The Microstructure of Foreign Exchange Markets, J. A. Frankel, G. Galli, and A. Giovannini, eds. Chicago: University of Chicago Press (1996 ).

Hamilton, J.D., 1994. Time Series Analysis. (Princeton: Princeton University Press).

Harris, L.E. "Estimation of Stock Price Variances and Serial Covariances From Discrete Observations." Journal of Financial and Quantitative Analysis, 25 (1990a), 291306.

Harris, L.E. "Statistical Properties of the Roll Serial Covariance Bid/Ask Spread Estimator." Journal of Finance, 45 (1990b), 579-90.

Harris, L.E. "Stock Price Clustering and Discreteness." Review of Financial Studies, 4 (1991), 389-415.

Harris, L.E. "Minimum Price Variations, Discrete Bid-Ask Spreads, and Quotation Sizes." Review of Financial Studies, 7 (1994), 149-78.

Harris, L. E. "Decimalization: A Review of the Arguments and Evidence." University of Southern California (1997a).

Harris, L. E. "Does a Large Minimum Price Variation Encourage Order Exposure?" School of Business Administration, University of Southern California (1997b).

Hasbrouck, J. "Trades, Quotes, Inventories, and Information." Journal of Financial Economics, 22 (1988), 229-52.

Hasbrouck, J. "Measuring the Information Content of Stock Trades." Journal of Finance, 46 (1991a), 179-207.

Hasbrouck, J. "The Summary Informativeness of Stock Trades: An Econometric Analysis." Review of Financial Studies, 4 (1991b), 571-95. 
Hasbrouck, J. "Using the TORQ Database." New York Stock Exchange (1992).

Hasbrouck, J. "Modeling Microstructure Time Series." in Handbook of Statistics 14: Statistical Methods in Finance, G. S. Maddala and C.R. Rao, eds. Amsterdam: Elsevier North Holland (1996a).

Hasbrouck, J. "Order Characteristics and Stock Price Evolution: an Application to Program Trading." Journal of Financial Economics, 41 (1996b), 129-49.

Hasbrouck, J. "The Dynamics of Discrete Bid and Ask Quotes." Journal of Finance, 54 (1999a), 2109-42.

Hasbrouck, J. "Security Bid/Ask Dynamics With Discreteness and Clustering: Simple Strategies for Modeling and Estimation." Journal of Financial Markets, 2 (1999b), 1-28.

Hasbrouck, J. "Trading Costs and Returns for US Equities: the Evidence From Daily Data." Stern School of Business New York University (2003).

Hasbrouck, J., and T.S.Y. Ho. "Order Arrival, Quote Behavior, and the ReturnGenerating Process." Journal of Finance, 42 (1987), 1035-48.

Holthausen, R.W., R.W. Leftwich, and D. Mayers. "The Effect of Large Block Transactions on Security Prices." Journal of Financial Economics, 19 (1987), $237-67$.

Holthausen, R.W., R.W. Leftwich, and D. Mayers. "Large Block Transactions, the Speed of Response, and Temporary and Permanent Stock Price Effects." Journal of Financial Economics, 26 (1990), 71-95.

Huang, R., and H. Stoll. " The Components of the Bid-Ask Spread: a General Approach." Review of Financial Studies, 10 (1997), 995-1034. 
Huang, R.D., and H.R. Stoll. "Market Microstructure and Stock Return Predictions." Review of Financial Studies, 7 (1994), 179-213.

Jacquier, E., N.G. Polson, and P.E. Rossi. "Bayesian Analysis of Stochastic Volatility Models." Journal of Business and Economic Statistics, 12 (1994), 371-89.

Jones, C. S. "The Dynamics of Stochastic Volatility: Evidence From Underlying and Options Markets." Simon School of Business Rochester University (2002).

Kandel, E., and L.M. Marx. "NASDAQ Market Structure and Spread Patterns." Journal of Financial Economics, 45 (1997), 61-89.

Kim, C.-J., and C. R. Nelson. State-space models with regime switching. Cambridge, Massachusetts: MIT Press (2000).

Kim, S., N. Shephard, and S. Chib. "Stochastic Volatility: Likelihood Inference and Comparison With ARCH Models." Review of Economic Studies, forthcoming (1998).

Laux, P.A., and A.J.Jr. Senchack. "Bid-Ask Spreads in Financial Futures." Journal of Futures Markets, 12 (1992), 621-34.

Lee, C.M.C., and M.J. Ready. "Inferring Trade Direction From Intraday Data." Journal of Finance, 46 (1991), 733-46.

Locke, P.R., and P.C. Venkatesh. "Futures Market Transactions Costs." Journal of Futures Markets, 17 (1997), 229-45.

Lyons, R.K. "Tests of Microstructural Hypotheses in the Foreign Exchange Market." Journal of Financial Economics, 39 (1995), 321-51.

Lyons, R.K. "A Simultaneous Trade Model of the Foreign Exchange Hot Potato." Journal of International Economics, 42 (1997), 275-98. 
Lyons, R. K. The Microstructure Approach to Foreign Exchange Rates. Cambridge, MA: MIT Press (2001).

Ma, C.K., R.L. Peterson, and R.S. Sears. "Trading Noise, Adverse Selection and Intraday Bid-Ask Spreads in Futures Markets." Journal of Futures Markets, 12 (1992), $519-38$.

Madhavan, A., M. Richardson, and M. Roomans. "Why Do Security Prices Change?" Review of Financial Studies, 10 (1997), 1035-64.

Manaster, S., and S.C. Mann. "Life in the Pits: Competitive Market Making and Inventory Control." Review of Financial Studies, 9 (1996), 953-75.

O'Hara, M. Market Microstructure Theory. Cambridge, MA: Blackwell Publishers (1995).

Odders-White, E. R. "On the Occurrence and Consequences of Inaccurate Trade Classification." University of Wisconsin (1997).

Roll, R. "A Simple Implicit Measure of the Effective Bid-Ask Spread in an Efficient Market." Journal of Finance, 39 (1984), 1127-39.

Schwert, G.W. "Symposium on Market Microstructure: Focus on NASDAQ." Journal of Financial Economics, 45 (1997), 1-8.

Shephard, N. "Fitting Nonlinear Time-Series Models With Applications to Stochastic Variance Models." Journal of Applied Econometrics, 8 (1993), S135-S152.

Smith, T., and R.E. Whaley. "Estimating the Effective Bid/Ask Spread From Time and Sales Data." Journal of Futures Markets, 14 (1994), 437-55.

Subrahmanyam, A. "A Theory of Trading in Stock Index Futures." Review of Financial Studies, 4 (1991), 17-51. 
U.S. Securities and Exchange Commission. 2001. Final rule: Disclosure of order routing and execution practices. 


\section{Table 1. Contract Descriptions and Summary Sample Statistics}

Contracts traded on the Chicago Mercantile Exchange for the indicated underlying and maturity.

\begin{tabular}{|c|c|c|c|c|}
\hline & \multicolumn{4}{|c|}{ Contract } \\
\hline & Pork Bellies & Euro FX & $\mathrm{UK} £$ & S\&P 500 \\
\hline Expiration month & Feb. 2000 & Sep. 1999 & Sep. 1999 & Sep. 1999 \\
\hline Trading sample month & Sep. 1999 & Aug. 1999 & Aug. 1999 & Aug. 1999 \\
\hline Number of Trading Days & 20 & 22 & 22 & 22 \\
\hline Total Number of Trades & 3,882 & 9,869 & 9,414 & 106,402 \\
\hline Average Price & 57.83 & 1.06 & 1.61 & $1,331.67$ \\
\hline Price Units & Cents/Lb & US\$/Euro & US\$/UK£ & Index Pts \\
\hline Tick & 0.025 & 0.0001 & 0.0002 & 0.1 \\
\hline Average Tick/Price & $0.043 \%$ & $0.009 \%$ & $0.012 \%$ & $0.008 \%$ \\
\hline Size of Contract & \multicolumn{2}{|c|}{$40,000 \mathrm{Lb} 125,000 \mathrm{Eu}$} & \multicolumn{2}{|c|}{$62,500 £ \$ 250 x$ Index } \\
\hline Average Dollar Value $(\$ 1,000)$ & 23.1 & 132.8 & 10.05 & 332.9 \\
\hline $\begin{array}{l}\text { Std. Dev. of price change } \\
(\log \text { price } \times 10,000)\end{array}$ & 20.6 & 1.9 & 1.67 & 2.5 \\
\hline Std. Dev. of price change (ticks) & 4.79 & 1.99 & 1.3 & 3.30 \\
\hline Average daily trades & 194 & 449 & 428 & 4,836 \\
\hline Avg time between trade (sec.) & 70.8 & 53.9 & 56.5 & 5.1 \\
\hline \multicolumn{5}{|l|}{ Distribution of trade sizes: } \\
\hline Min & 1 & 1 & 1 & 1 \\
\hline 25\%'ile & 1 & 2 & 1 & 2 \\
\hline Median & 2 & 4 & 3 & 6 \\
\hline $75 \%$ 'ile & 3 & 10 & 8 & 18 \\
\hline Max & 140 & 420 & 374 & 713 \\
\hline
\end{tabular}




\section{Table 2. Estimates of the Roll Model.}

Sample of CME contracts described in Table 1. $\sigma_{u}$ is the standard deviation of the log efficient price changes; $c$ is the (log) half-spread; $C$ is the half-spread in ticks. Estimates labeled "Bayes, $q$ simulated" are Gibbs sampler estimates in which the trade direction indicators $q$ are conditionally simulated. Results are based on 10,000 sweeps of the sampler, with the first 2,000 discarded. Standard errors of the posterior means (SEM's) are corrected for autocorrelation in the draws (using spectral averages). The alternate estimates labeled "Bayes, $q$ fixed" are Gibbs sampler estimates in which the $q$ are assigned using a tick rule. Moment estimates are the conventional autocovariance-based estimates of the model.

\begin{tabular}{|c|c|c|c|c|c|c|}
\hline \multirow[b]{3}{*}{ Contract } & \multirow[b]{3}{*}{ Parameter } & \multicolumn{3}{|c|}{ Primary Estimates } & \multicolumn{2}{|c|}{ Alternative Estimates } \\
\hline & & \multicolumn{3}{|c|}{ Bayes, $q$ simulated } & \multirow{2}{*}{$\begin{array}{c}\text { Moment } \\
\text { Point } \\
\text { Estimate }\end{array}$} & \multirow{2}{*}{$\begin{array}{l}\begin{array}{l}\text { Bayes, } \\
q \text { fixed }\end{array} \\
\begin{array}{c}\text { Posterior } \\
\text { Mean }\end{array} \\
\end{array}$} \\
\hline & & $\begin{array}{c}\text { Posterior } \\
\text { Mean }\end{array}$ & SEM & $\begin{array}{l}\text { Posterior } \\
\text { Std. Dev. }\end{array}$ & & \\
\hline \multirow[t]{3}{*}{$\begin{array}{l}\text { Pork } \\
\text { Belly }\end{array}$} & $\sigma_{u} \times 10,000$ & 20.24 & 0.0118 & 0.312 & 19.41 & 20.58 \\
\hline & $c \times 10,000$ & 2.52 & 0.0516 & 0.930 & 4.86 & 9.22 \\
\hline & $C$ (ticks) & 0.58 & 0.0119 & 0.215 & 1.12 & 2.13 \\
\hline \multirow[t]{3}{*}{ Euro } & $\sigma_{u} \times 10,000$ & 1.86 & 0.0005 & 0.016 & 1.79 & 1.87 \\
\hline & $c \times 10,000$ & 0.17 & 0.0033 & 0.053 & 0.40 & 0.24 \\
\hline & $C($ ticks $)$ & 0.18 & 0.0035 & 0.057 & 0.43 & 0.25 \\
\hline \multirow[t]{3}{*}{$\mathrm{UK} £$} & $\sigma_{u} \times 10,000$ & 1.60 & 0.0007 & 0.018 & 1.54 & 1.67 \\
\hline & $c \times 10,000$ & 0.34 & 0.0017 & 0.036 & 0.47 & 0.24 \\
\hline & $C$ (ticks) & 0.28 & 0.0014 & 0.029 & 0.37 & 0.19 \\
\hline \multirow[t]{3}{*}{ S\&P } & $\sigma_{u} \times 10,000$ & 2.47 & 0.0001 & 0.006 & 1.30 & 2.48 \\
\hline & $c \times 10,000$ & 0.13 & 0.0005 & 0.013 & 1.49 & 3.46 \\
\hline & $C($ ticks $)$ & 0.17 & 0.0006 & 0.017 & 1.99 & 4.61 \\
\hline
\end{tabular}




\section{Table 3. Excess Transaction Price Clustering}

All CME trades in the indicated contracts from January 5 to January 16, 1998. The clustering frequency is $f_{\kappa}^{C}=f_{\kappa}-(1 / \kappa)$ where $f_{\kappa}$ is the sample frequency of trades prices that fall on a $\kappa$-multiple of the minimum tick. (Since $1 / \kappa$ is the expected value under the null hypothesis of uniformly distributed prices, $f_{\kappa}^{C}$ measures excess clustering.)

\begin{tabular}{crrrr}
\hline $\begin{array}{c}\text { Tick } \\
\text { Multiple } \kappa\end{array}$ & \multicolumn{1}{c}{$\begin{array}{c}\text { Pork } \\
\text { Bellies }\end{array}$} & \multicolumn{1}{c}{ Euro } & UK $£$ & S\&P 500 \\
\hline 2 & $39 \%$ & $2 \%$ & $0 \%$ & $3 \%$ \\
4 & $30 \%$ & $1 \%$ & $0 \%$ & $1 \%$ \\
5 & $2 \%$ & $3 \%$ & $2 \%$ & $28 \%$ \\
8 & $16 \%$ & $1 \%$ & $0 \%$ & $1 \%$ \\
10 & $11 \%$ & $2 \%$ & $1 \%$ & $15 \%$ \\
\hline
\end{tabular}




\section{Table 4. Estimates of the Clustered Asymmetric Information Model}

Sample of CME contracts described in Table 1. The log efficient price dynamics are $\Delta m_{t}=\sum_{i=0}^{5} q_{t-i} \lambda_{i} v_{t-i}+u_{t}$ where $\lambda_{i}=\left(\begin{array}{ll}\lambda_{i, \text { Intercept }} & \lambda_{i, \text { Slope }}\end{array}\right)$ and $v_{t-i}=\left(\begin{array}{ll}1 & \sqrt{\text { volume }_{t}}\end{array}\right)^{\prime}$. $R_{\Delta m, T r a d e s}^{2}$ is the explained variance in this specification. $C$ is the implicit quote exposure $\operatorname{cost} ; k$ is the clustering intensity; $\kappa$ is the clustering multiple. Estimates are based on 2,000 Gibbs sweeps with the first 400 discarded. Standard errors of the posterior means (SEM) are corrected for autocorrelation in the draws (using spectral averages).

\begin{tabular}{|c|c|c|c|c|}
\hline Contract & Parameter & Post. Mean & SEM & Post. Std. Dev. \\
\hline \multirow{6}{*}{$\begin{array}{l}\text { Pork Belly } \\
(\kappa=2)\end{array}$} & $\sigma_{u} \times 10,000$ & 13.4926 & 0.0130 & 0.2096 \\
\hline & $C($ ticks $)$ & 0.3996 & 0.0200 & 0.1943 \\
\hline & $k$ & 0.7839 & 0.0004 & 0.0101 \\
\hline & $\sum \lambda_{i, \text { Intercept }} \times 10,000$ & 6.3902 & 0.0909 & 1.4365 \\
\hline & $\sum \lambda_{i, \text { Slope }} \times 10,000$ & 1.9517 & 0.0456 & 0.7812 \\
\hline & $R_{\Delta m, \text { Trades }}^{2}$ & 0.6113 & 0.0007 & 0.0089 \\
\hline \multirow{6}{*}{$\begin{array}{l}\text { Euro } \\
(\kappa=5)\end{array}$} & $\sigma_{u} \times 10,000$ & 1.3115 & 0.0006 & 0.0119 \\
\hline & $C($ ticks $)$ & 0.0143 & 0.0012 & 0.0136 \\
\hline & $k$ & 0.0258 & 0.0006 & 0.0061 \\
\hline & $\sum \lambda_{i, \text { Intercept }} \times 10,000$ & 2.4854 & 0.0088 & 0.1068 \\
\hline & $\sum \lambda_{i, \text { Slope }} \times 10,000$ & 0.0110 & 0.0017 & 0.0237 \\
\hline & $R_{\Delta m, \text { Trades }}^{2}$ & 0.5333 & 0.0003 & 0.0053 \\
\hline \multirow{6}{*}{$\begin{array}{l}\text { UK } £ \\
(\kappa=5)\end{array}$} & $\sigma_{u} \times 10,000$ & 1.0258 & 0.0006 & 0.0106 \\
\hline & $C($ ticks $)$ & 0.0077 & 0.0006 & 0.0076 \\
\hline & $k$ & 0.0023 & 0.0001 & 0.0008 \\
\hline & $\sum \lambda_{i, \text { Intercept }} \times 10,000$ & 1.9128 & 0.0057 & 0.0775 \\
\hline & $\sum \lambda_{i, \text { Slope }} \times 10,000$ & -0.0197 & 0.0018 & 0.0242 \\
\hline & $R_{\Delta m, \text { Trades }}^{2}$ & 0.6658 & 0.0003 & 0.0049 \\
\hline \multirow{6}{*}{$\begin{array}{l}\text { S \& P } \\
(\kappa=5)\end{array}$} & $\sigma_{u} \times 10,000$ & 2.2703 & 0.0012 & 0.0126 \\
\hline & $C($ ticks $)$ & 0.0841 & 0.0201 & 0.1906 \\
\hline & $k$ & 0.3179 & 0.0004 & 0.0042 \\
\hline & $\sum \lambda_{i, \text { Intercept }} \times 10,000$ & 0.4535 & 0.0132 & 0.1299 \\
\hline & $\sum \lambda_{i, \text { Slope }} \times 10,000$ & 0.0767 & 0.0006 & 0.0098 \\
\hline & $R_{\Delta m, \text { Trades }}^{2}$ & 0.0783 & 0.0028 & 0.0262 \\
\hline
\end{tabular}


Figure 1. Posterior Distributions for the Basic Roll Model.

Sample of CME contracts described in Table 1. $\sigma_{u}$ is the standard deviation of the log efficient price changes; $c$ is the $(\log )$ half-spread; $C$ is the half-spread in ticks. Histograms are based on 10,000 sweeps of the Gibbs sampler, with the first 2,000 discarded.

Pork Bellies

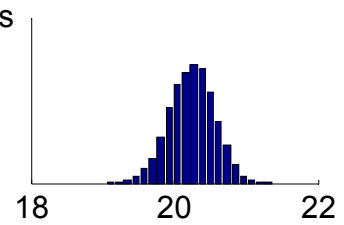

Euro

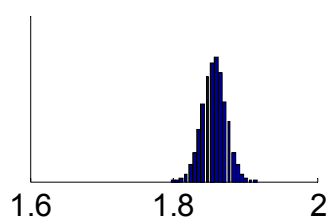

UK

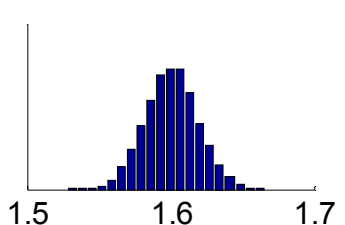

S\&P 500

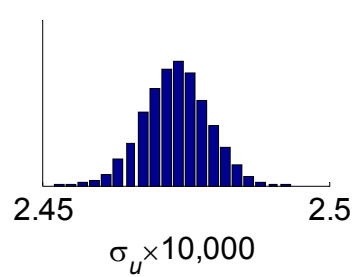

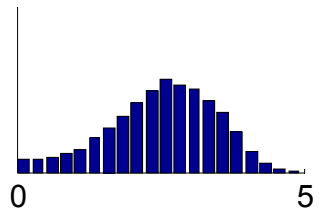
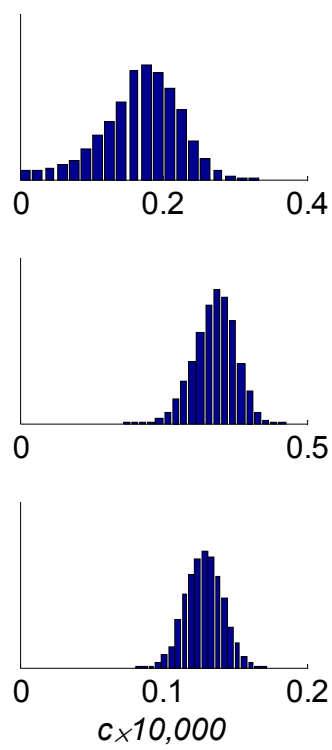
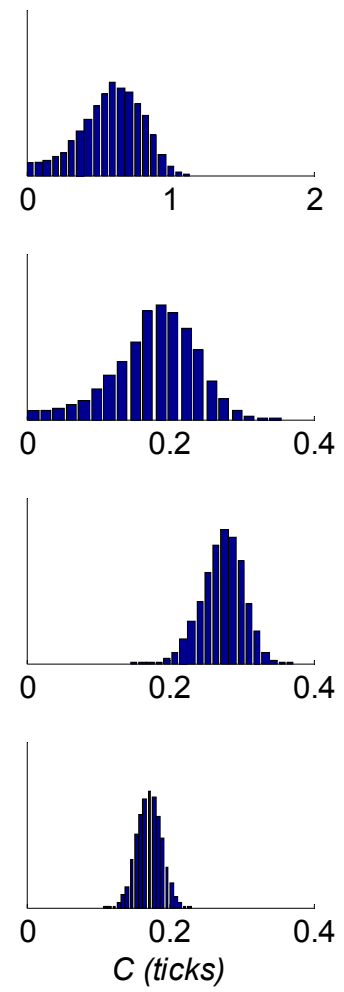


\section{Figure 2. Implied Trade Price Impacts}

Cumulative impact of a buy order on the log efficient price as a function of order size. Estimates based on clustered asymmetric information model with trade impact terms (through lag five). Dashed line indicates approximate tick size.
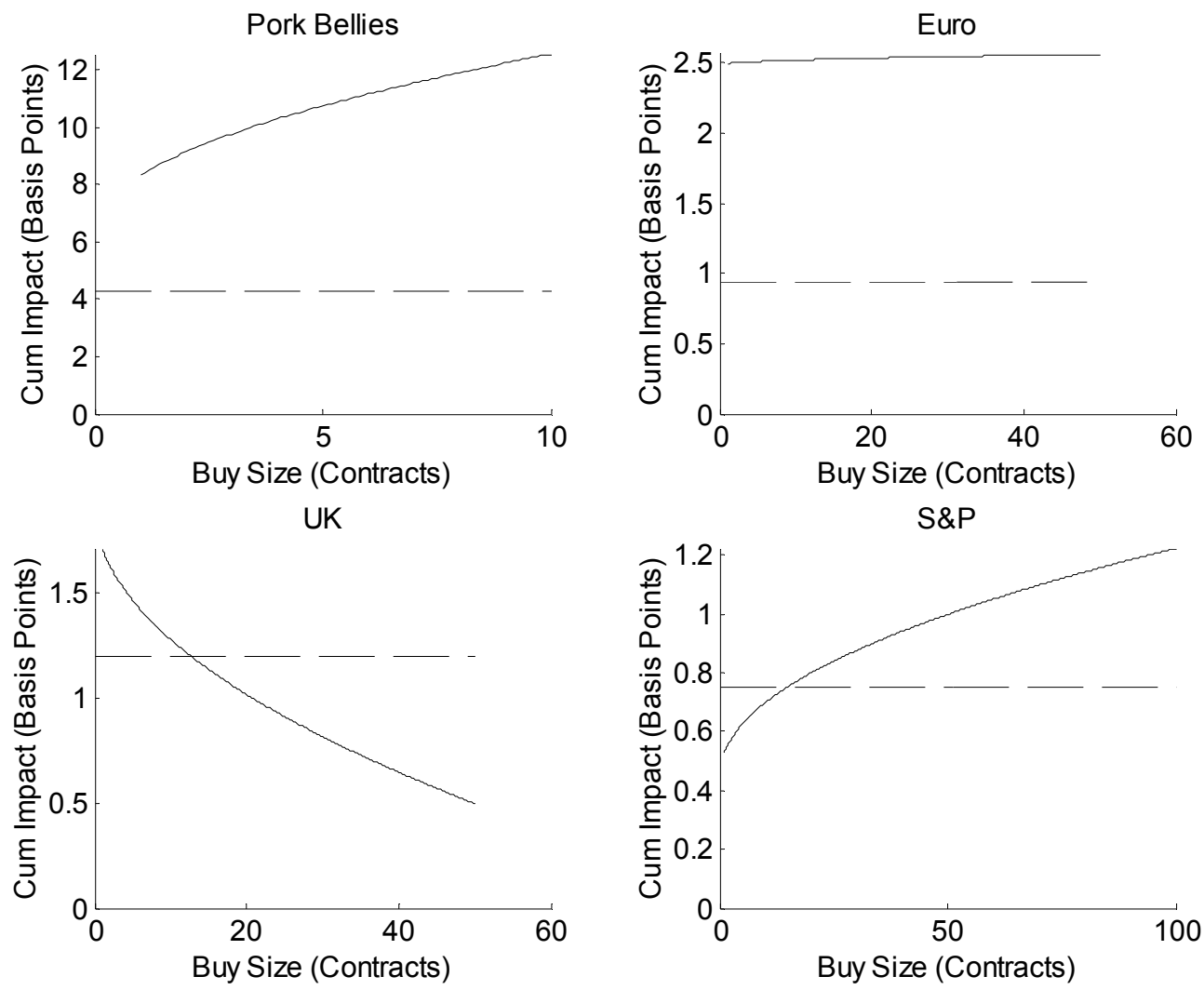